Article

\title{
Gust Alleviation of a Large Aircraft with a Passive Twist Wingtip
}

\author{
Shijun Guo *, Jaime Espinosa De Los Monteros and Ying Liu \\ Centre of Aeronautics, Aerospace Engineering, Cranfield University, Bedfordshire, MK43 0AL, UK; \\ E-Mails: jaimespinosadlm@gmail.com (J.E.L.M.); y.liu@cranfield.ac.uk (Y.L.) \\ * Author to whom correspondence should be addressed; E-Mail: s.guo@cranfield.ac.uk; \\ Tel.: +44-1234754628; Fax: +44-1234758203.
}

Academic Editor: Konstantinos Kontis

Received: 4 March 2015 / Accepted: 26 March 2015 / Published: 3 April 2015

\begin{abstract}
This paper presents an investigation into the gust response and wing structure load alleviation of a 200-seater aircraft by employing a passive twist wingtip (PTWT). The research was divided into three stages. The first stage was the design and analysis of the baseline aircraft, including aerodynamic analysis, structural design using the finite element (FE) method and flutter analysis to meet the design requirements. Dynamic response analysis of the aircraft to discrete (one-cosin) gust was also performed in a range of gust radiances specified in the airworthiness standards. In the second stage, a PTWT of a length of $1.13 \mathrm{~m}$ was designed with the key parameters determined based on design constraints and, in particular, the aeroelastic stability and gust response. Subsequent gust response analysis was performed to evaluate the effectiveness of the PTWT for gust alleviation. The results show that the PTWT produced a significant reduction of gust-induced wingtip deflection by $21 \%$ and the bending moment at the wing root by $14 \%$ in the most critical flight case. In the third stage, effort was made to study the interaction and influence of the PTWT on the symmetric and unsymmetrical manoeuvring of the aircraft when ailerons were in operation. The results show the that PTWT influence with a reduction of the aircraft normal velocity and heave motion by $1.7 \%$ and $3 \%$, respectively, is negligible. However, the PTWT influence on the aircraft roll moment with a $20.5 \%$ reduction is significant. A locking system is therefore required in such a manoeuvring condition. The investigation has shown that the PTWT is an effective means for gust alleviation and, therefore, has potential for large aircraft application.
\end{abstract}


Keywords: wing structure; passive twist wingtip; gust alleviation; aeroelastic stability

\section{Introduction}

Aircraft will be inevitably exposed to atmospheric disturbances or gust of different degrees of severity during flight. The gust produces extra aerodynamic forces on the structure, especially the wing, and leads to the dynamic responses of the aircraft with undesired transverse movement. For some aircraft, the gust load is greater than the manoeuvring load and produces the most critical load case in the structure design. For civil airliners, especially with a high aspect ratio wing, the gust response causes concerns for the airframe safety, riding comfort and handling quality. To ensure aircraft safety, airworthiness authorities have specified a typical gust model and parameters as part of the certification requirements for structure design. Modern aircraft structures have been significantly improved by employing composite materials and advanced alloys. Nevertheless, gust load will cause an increase of the airframe weight, reduction of the structural fatigue life and higher maintenance cost. It is therefore desirable to alleviate the gust load by means of an active or passive control system in the first place.

In fact, various active and passive control technologies have been developed for flutter suppression and gust alleviation, and some been applied to aircraft [1-5]. Comparing with the active control system, a passive control device is usually simpler and more reliable, although, maybe, less effective. This current investigation is focused on the effectiveness of gust alleviation by a specially-designed passive twist wingtip (PTWT). This particular PTWT has been studied in previous research for large unmanned air vehicles, including a flying wing aircraft [6,7] and jointed-wing sensor craft [8-12] of very flexible and high aspect ratio wings. The results have shown that the gust load has been significantly reduced by employing such a passive gust load alleviation device with optimized design parameters.

This current investigation is aimed at evaluating the feasibility and effectiveness of the PTWT for gust response alleviation of a large civil aircraft of a high aspect ratio wing and conventional configuration. The example aircraft taken in the case study is a 200 -seater airliner designed in an MSc group design project at Cranfield University in 2013 [20]. The technical details are presented in Section 3 . The study was conducted in three stages.

In the first stage, to ensure that the analysis and results are representable in general cases, the design and modelling of the example aircraft was carried out to meet the airworthiness requirements. Starting with the aerodynamic loading analysis, the composite wing structure was modelled and analysed by using the finite element (FE) method. Subsequent modal and flutter analysis was carried out to satisfy the aeroelastic design constraint. For this baseline aircraft model, gust response analysis to a discrete (one-cosin) gust was performed in a range of gust velocities and gradients specified in the airworthiness European Aviation Safety Agency (EASA) CS-25 [13].

In the second stage, an FE model of the passive twist wingtip (PTWT) of $1.13 \mathrm{~m}$ in length was created to replace the baseline wingtip. The key design parameters of the PTWT were determined for maximum gust alleviation subject to the required aeroelastic stability and normal operation at cruising. 
Gust response analysis of the wing and the whole aircraft with free heave motion was subsequently performed to evaluate the effectiveness of the PTWT in the specified gust range. The analysis results have shown that a significant reduction of gust response by employing the PTWT has been achieved in terms of the wing deflection and bending moment.

In the third stage, the investigation was extended to the influence of the PTWT on the control effectiveness of the aircraft in symmetric and unsymmetrical manoeuvrability. Although additional aerodynamic force will be produced mainly in the wing sections where ailerons were operated, the PTWT will react to the operation to some extent and have a potentially negative effect. In the case that the negative effect is unacceptable, a PTWT locking system would be necessary. The investigation has shown that the PTWT is a reliable and very effective approach to alleviate gust load and, therefore, has the potential for application.

\section{Design Requirements and Analysis Methods}

\subsection{Design Requirements and Procedure}

Based on the conceptual design of an aircraft, the most critical load conditions are identified for the preliminary design of structures. For a large civil aircraft, the design has to comply with the CS-25 airworthiness requirements. In this investigation, the buckling analysis method [14] under practical design constraints [15] has been used in the stiffened skin panel design. For a wing made of carbon/epoxy composite materials, the usual laminate strength criteria in terms of the failure index (FI) are used for strength evaluation. One of the three widely used interactive failure criteria, the Tsai-Wu criterion, was also employed, since the other two would give similar results with negligible differences. In addition, the maximum strain of the structural laminate components is limited to $\varepsilon=0.0035(3500 \mu \varepsilon)$ under the damage tolerance constraint. This figure was used as a general guideline for composite structure design in a world-leading civil aircraft industry.

Based on the preliminary design, the wing structure was modelled and analysed using the FE method, implemented in the Patran/Nastran package. After the static analysis to ensure the structural stiffness and strength requirements are satisfied, the modal and flutter analysis and dynamic response of the wing to 1-cosin discrete gust was conducted in a range of gust lengths specified in CS-25. The original 200-seater airliner having a conventional wing without the PTWT is taken as the baseline model. The PTWT FE model is then created to replace the baseline wingtip. Firstly, the PTWT effectiveness on gust alleviation was evaluated only for the wing clamped at the root. Subsequently, the gust alleviation was analysed for the whole aircraft with the fuselage and tail modelled as rigid bodies. Finally, concerning the potential influence of the PTWT on the flight performance, analysis was conducted on the symmetrical and unsymmetrical manoeuvring of the aircraft.

\subsection{Aeroelastic Analysis}

The aeroelastic analysis for large aircraft is normally performed in a generalized coordinate system in the frequency domain. The aeroelastic governing equations in matrix form can be expressed as below [16]. 


$$
\left[-M_{h h} p^{2}+\left(D_{h h}-\frac{1}{4} \rho V c Q_{h h}^{I}(M, k) / k\right)+\left(K_{h h}-\frac{1}{2} \rho V^{2} Q_{h h}^{R}(M, k)\right)\right]\left\{q_{h}\right\}=\left\{Q_{G}\right\}
$$

where $M_{\mathrm{hh}}, D_{\mathrm{hh}}$ and $K_{\mathrm{hh}}$ are the generalized mass, damping and stiffness matrix, respectively; $M$ is the Mach number; $k$ is the reduced frequency; $\left\{q_{\mathrm{h}}\right\}$ is the generalized coordinate vector; $Q_{h h}^{R}$ and $Q_{h h}^{I}$ are the real and imaginary parts of the generalized unsteady aerodynamic matrix $Q_{h h}=[\Phi]^{T}\left\{L_{\mathrm{hh}}\right\}[\Phi]$, where $\left\{L_{\mathrm{hh}}\right\}$ is the unsteady aerodynamic force vector and $[\Phi]$ the modal matrix of the structure in spatial coordinates; $\left\{Q_{G}\right\}=[\Phi]^{T}\left\{L_{\mathrm{G}}\right\}$ is the generalized aerodynamic force due to gust, where $\left\{L_{\mathrm{G}}\right\}$ is the gust-induced aerodynamic force vector based on the gust model with details presented in the section below.

The unsteady aerodynamic force is calculated by using the doublet-lattice method $[17,18]$ in Nastran. In the aerodynamic modelling, the airfoil profile effect is ignored, since it has been considered in the steady aerodynamic calculation. The wing surface is divided into planar trapezoidal segments, each having a constant dihedral with the sides parallel to the flow direction. These segments are further divided into panels with aspect ratios between $1 / 3$ and 3.0. Higher density mesh is taken near the wing edges and those regions where discontinuous downwash and pressures of large gradients occur. The structural FE stress and modal analysis is performed by using Nastran. When both aerodynamic grids and structural meshes are created, a surface spline method was used to interpolate the aerodynamic grid points to structural mesh points for aeroelastic analysis.

For flutter analysis, the $\left\{Q_{\mathrm{G}}\right\}$ term in Equation (1) is zero, and the equation is then solved to determine the flutter speed by using the "pk" method. For gust response analysis with non-zero $\left\{Q_{\mathrm{G}}\right\}$, the $\left\{q_{\mathrm{h}}\right\}$ is solved and transformed back to the displacement in space coordinates. Both calculations use the aeroelastic module built in to Nastran.

\subsection{Gust Model and Load}

The air turbulence in real life encountered in flight is usually random and continuous in a short period. For large aircraft design purposes, two types of air turbulence models are accepted and specified in the airworthiness regulation CS-25. One is a continuous model of random characteristics represented by the power spectrum density and another simplified discrete gust model, such as the 1-cosine model. The external gust aerodynamic force and response depends on the input gust model. In this study, the main concern is the relative gust response of an aircraft with the PTWT compared with the baseline rather than the absolute value of the gust response. The 1-cosin discrete gust model is thus adapted in this current investigation. The gust velocity profile is expressed below [13]:

$$
U=\frac{U_{d s}}{2}\left(1-\cos \frac{\pi s}{H}\right) ; 0 \leq s \leq 2 H
$$

where $U_{\mathrm{ds}}$ is a specified design gust velocity, $s$ is the distance of the aircraft penetrated in the gust and $H$ is the gust gradient distance, which is the distance parallel to the airplane's flight path for the gust to reach its peak velocity. According to CS-25, the gust distance $H$ is in the range from 9 to $107 \mathrm{~m}$, including a typical value $12.5 \bar{c}$, where $\bar{c}$ is the wing mean chord.

For an aircraft flying at speed $V$ and encountering a discrete gust modelled by Equation (2), the gust penetrating distance is $s=V t$, and Equation (2) can be rewritten as $0.5 U_{\mathrm{ds}}(1-\cos (\pi V t / H))$ or $0.5 U_{\mathrm{ds}}(1-\cos (\omega t))$ in the time-domain. From this expression, an equivalent gust frequency for the 
dynamic response analysis can be calculated as $\omega=\pi V / H$ in radians or $\omega=V / 2 H$ in $\mathrm{Hz}$. The design gust velocity $\left(U_{\mathrm{ds}}\right)$, as defined in CS-25, can be calculated as follows:

$$
U_{d s}=U_{r e f} F_{g}\left(\frac{H}{107}\right)^{1 / 6}
$$

where the reference gust velocity $U_{\text {ref }}$ or gust intensity depends on the equivalent airspeed (EAS) and altitude and is specified in CS-25. At speeds between stall speed and cruise speed $V_{\mathrm{C}}, U_{\text {ref }}=17.03 \mathrm{~m} / \mathrm{s}$ at sea level; linearly decreasing to $13.41 \mathrm{~m} / \mathrm{s}$ from sea level to $15,000 \mathrm{ft}$; further linearly decreasing to $6.36 \mathrm{~m} / \mathrm{s}$ from 15,000 to $60,000 \mathrm{ft}$. At dive speed $V_{\mathrm{D}}, U_{\text {ref }}$ takes half of the specified value for $V_{\mathrm{C}}$. The $F_{\mathrm{g}}$ is defined as the flight profile alleviation factor and expressed below. It increases linearly from sea level to 1.0 at the maximum operating altitude $Z_{\mathrm{mo}}$ as follows [13]:

$$
F_{g}=0.5\left(F_{g z}+F_{g m}\right)
$$

where $F_{g z}=1-\frac{Z_{m o}}{76,200[m]} ; F_{g m}=\sqrt{R_{2} \tan \left(\frac{\pi R_{1}}{4}\right)} ; R_{1}=\frac{M L M}{M T O M} ; R_{2}=\frac{M Z F M}{M T O M} ;$ and the parameters MTOM, MLM and MZFM represent the maximum take-off mass, maximum landing mass and maximum zero fuel mass of the aircraft, respectively.

According to the gust velocity, the aerodynamic force due to the gust can be calculated from:

$$
L_{G}=\frac{1}{2} \rho V_{0}^{2} s a_{1} F \frac{U}{V_{0}}
$$

where $\rho$ is the air density, $s$ is the reference area of the wing, $a_{1}$ is the lift curve slope of the wing and $V_{0}$ is the equivalent flight speed. For a symmetric vertical gust, the gust alleviating factor is defined as:

$$
F=\frac{0.88 \mu}{5.3+\mu}
$$

where $\mu=\frac{2 m}{\rho s \bar{c} a_{1}}$ is the mass parameter, $m$ is the mass of the aircraft and $\bar{c}$ is the wing mean chord.

Substituting the following expression of aerodynamic force into Equation (5),

$$
L=\frac{1}{2} \rho V_{0}^{2} s C_{L}
$$

Equation (5) can be rewritten in proportion to the steady aerodynamic force as:

$$
L_{G}=\frac{a_{1} F U}{C_{L} V_{0}} L
$$

The gust-induced aerodynamic force $L_{\mathrm{G}}$ was transformed to the generalized form $\left\{Q_{\mathrm{G}}\right\}$, as defined earlier, and used to calculate the structural response in terms of deflection based on Equation (1).

\section{Aircraft Design Example and Results}

\subsection{Aircraft Data and Aerodynamic Load}

The 200-seater airliner as illustrated in Figure 1a is taken as the baseline airframe. This aircraft has an H-tail, and twin open-rotor engines are mounted above the rear fuselage. This configuration makes the high aspect ratio wing clean for high aerodynamic efficiency, but also sensitive to gust load. The cruise speed (EAS) is Mach 0.78 or $231 \mathrm{~m} / \mathrm{s}$ at an altitude of 35,000 ft. Some additional technical 
data of the aircraft design are listed in Table 1. The aerodynamic force distributions over the wing in trimmed level flight and under gust load without and with the PTWT in action are illustrated in Figure $1 \mathrm{~b}$.

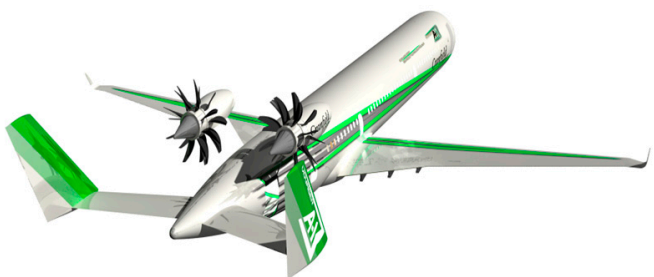

(a)

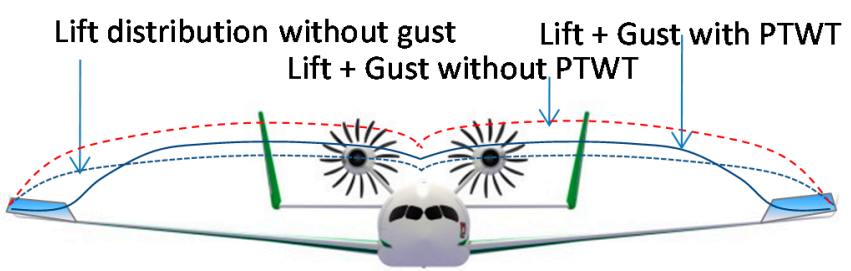

(b)

Figure 1. (a) The aircraft configuration and (b) the aerodynamic force distributions in three cases. PTWT, passive twist wingtip.

Table 1. Technical data for the aircraft design.

\begin{tabular}{ccccccc}
\hline $\begin{array}{c}\text { Wing } \\
\text { Span (m) }\end{array}$ & $\begin{array}{c}\text { Aspect } \\
\text { Ratio }\end{array}$ & $\begin{array}{c}\text { Leading Edge } \\
\text { Sweep Angle (deg) }\end{array}$ & $\begin{array}{c}\text { Fuselage } \\
\text { Length (m) }\end{array}$ & $\begin{array}{c}\text { MTOM (Maximum } \\
\text { Take-Off Mass) (kg) }\end{array}$ & $\begin{array}{c}\text { OEM (Operation } \\
\text { Empty Mass) }\end{array}$ (kg) & $\begin{array}{c}\text { Cruise } \\
\text { Altitude (feet) }\end{array}$ \\
\hline 38.3 & 12 & 5.0 & 44.5 & $87,663.0$ & $46,500.0$ & 35,000 \\
\hline
\end{tabular}

The wing airfoil chosen for the aircraft is a supercritical profile to keep natural laminar flow in cruise. To identify the most critical loading case for wing structure design, the initial analysis of aerodynamic loads in the combination of various manoeuvre cases was carried out based on lifting line theory and elliptical approximation of the spanwise lift distribution [19]. For validation purposes, numerical simulation of the aerodynamic loads was subsequently performed by using the Fluent Package based on computational fluid dynamics (CFD) method. In the steady aerodynamic analysis, the aeroelastic effect was ignored. Figure 2 shows the aerodynamic pressure on a $2 \mathrm{D}$ wing section and the whole $3 \mathrm{D}$ wing at an angle of attack $(\mathrm{AoA})=5.54^{\circ}$. The difference of the resulting wingtip deflections due to the aerodynamic forces by the lifting line and CFD methods is within 5\%, with the CFD results slightly greater [20].

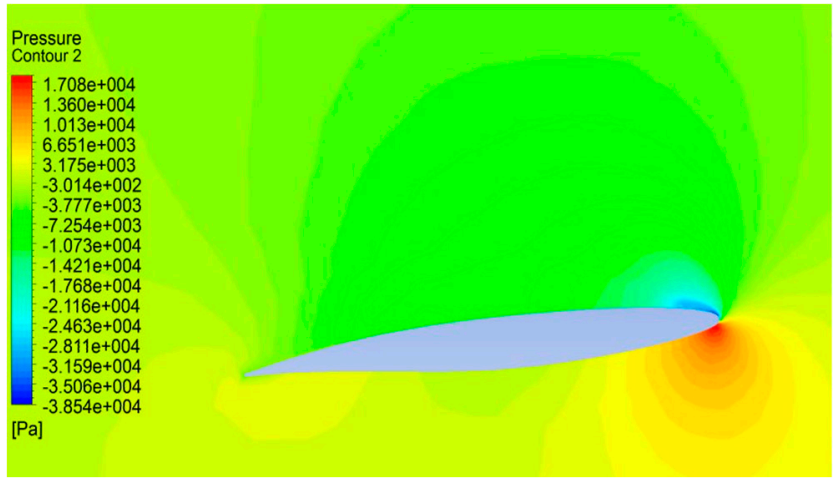

(a)

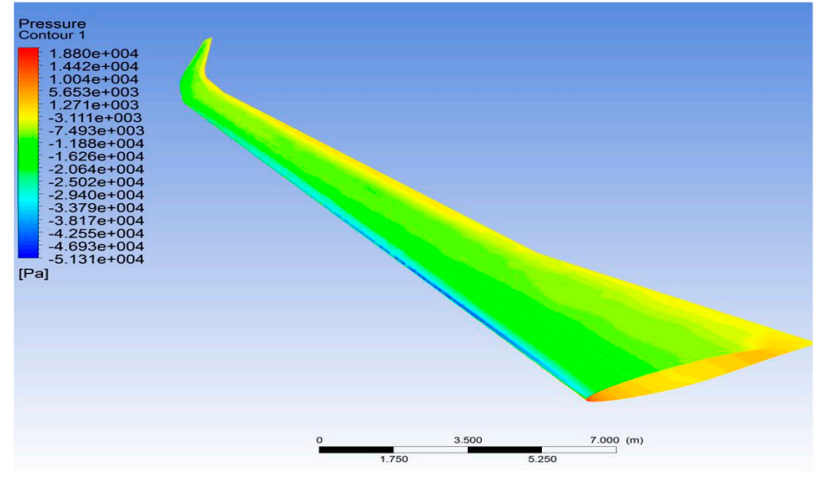

(b)

Figure 2. (a) Aerodynamic pressure over a $2 \mathrm{D}$ wing section and (b) the whole $3 \mathrm{D}$ wing. 
In this result, only the aerodynamic washout due to the spanwise jig angle was counted in the 3D wing shape. The aeroelastic washout due to structural deformation was not considered at this stage, since the influence would not be significant due to the small sweep angle of the wing.

The most critical load on the wing for structure design was calculated using the lifting line method by combining the aerodynamic forces for each section in the worst, but possible, conditions. It is usually represented in the form of shear force and the associated bending moment plot along the wingspan, as shown in Figure 3. The torque distribution along the wing span is similar to the bending moment and results in a maximum value of $1,000 \mathrm{kNm}$ at the wing root. To simplify the aerodynamic analysis, the winglet was ignored in the current study. This led to the wingtip aerodynamic performance and, consequently, the effectiveness of PTWT gust alleviation being underestimated.

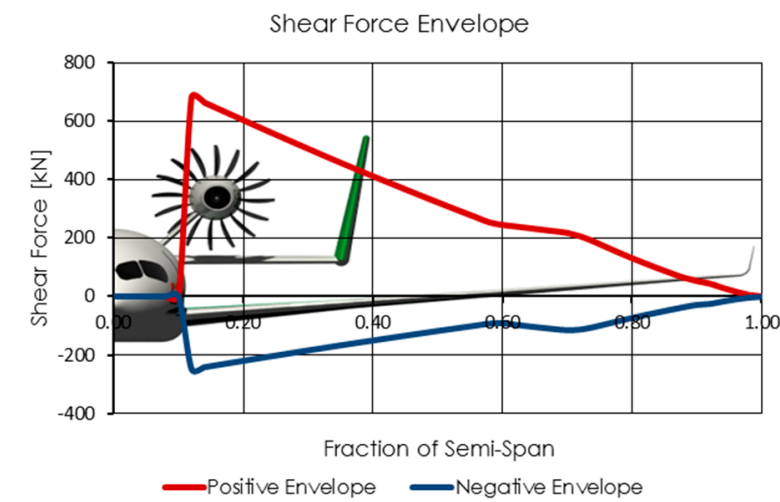

(a)

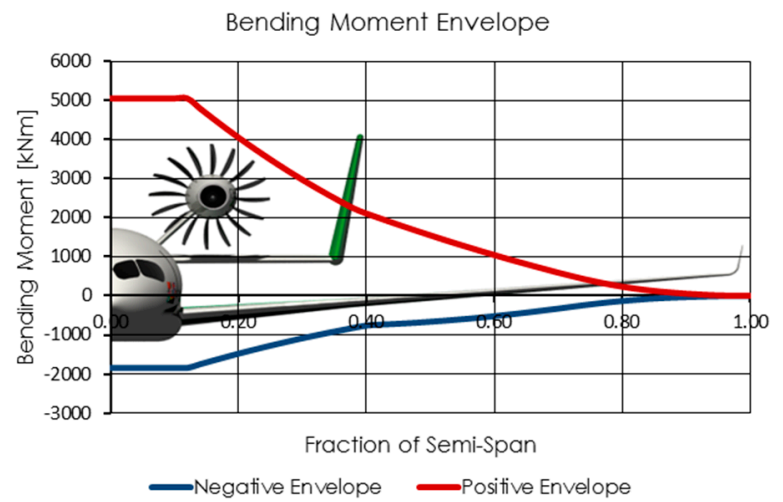

(b)

Figure 3. (a) The most critical shear force and (b) bending moment distribution along the wing span.

\subsection{Structural Layout and Initial Design}

The conventional structure layout of the fuselage and wing of the aircraft design has been adapted as illustrated in Figure 4a. The chordwise dimension of the flaps and aileron is $30 \%$ chord. The spanwise position and dimension of the aileron and elevator are also shown in Figure 4a. The primary structure of the composite wing is made of the upper and lower stiffened skin covers and 21 ribs supported by a front spar and rear spar located at $15 \%$ and $65 \%$ chord, respectively. Top-hat stringers and integral blade stringers with a spacing of $150 \mathrm{~mm}$ were selected to reinforce the upper and lower skin covers, respectively, as illustrated in Figure $4 \mathrm{~b}$. An intermediate modulus carbon/epoxy composite prepreg has been chosen with material modulus $E_{1}$ and strength $X_{\mathrm{t}}$ and $X_{\mathrm{c}}$ in the fibre direction, $E_{2}, Y_{\mathrm{t}}$ and $Y_{\mathrm{c}}$ in the off-fibre direction and shear modulus $G_{12}$, strength $S$ and Poisson's ratio $v_{12}$, presented in Table 2.

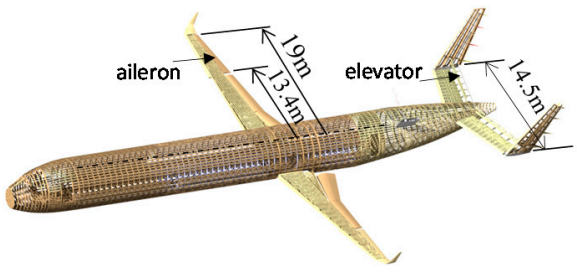

(a)

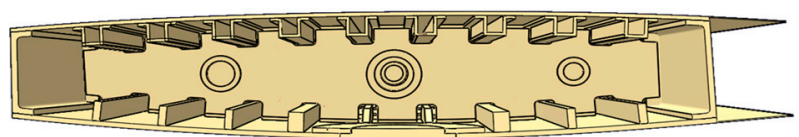

(b)

Figure 4. (a) Structural layout of the aircraft and (b) the cross-section view of the wing box. 
Table 2. Mechanical properties of the composite material (M91/IM10 UD prepreg) [21].

\begin{tabular}{cccccccccc}
\hline $\begin{array}{c}E_{\mathbf{1}} \\
(\mathbf{G P a})\end{array}$ & $\begin{array}{c}\boldsymbol{E}_{\mathbf{2}} \\
(\mathbf{G P a})\end{array}$ & $\begin{array}{c}\boldsymbol{G}_{\mathbf{1 2}} \\
(\mathbf{G P a})\end{array}$ & $\boldsymbol{v}_{\mathbf{1 2}}$ & $\begin{array}{c}\boldsymbol{X}_{\mathbf{t}} \\
(\mathbf{M P a})\end{array}$ & $\begin{array}{c}\boldsymbol{X}_{\mathbf{c}} \\
(\mathbf{M P a})\end{array}$ & $\begin{array}{c}\boldsymbol{Y}_{\mathbf{t}} \\
(\mathbf{M P a})\end{array}$ & $\begin{array}{c}\boldsymbol{Y}_{\mathbf{c}} \\
(\mathbf{M P a})\end{array}$ & $\begin{array}{c}\boldsymbol{S} \\
(\mathbf{M P a})\end{array}$ & $\begin{array}{c}\boldsymbol{\rho} \\
\left(\mathbf{k g} / \mathbf{m}^{\mathbf{3}}\right)\end{array}$ \\
\hline 176 & 15 & 5.6 & 0.27 & 3520 & 1880 & 42.7 & 127 & 105 & 1586 \\
\hline
\end{tabular}

Based on the loading and structural layout, an initial structural design with quasi-isotropic layup (50/40/10) (i.e., 50\%, $40 \%$ and $10 \%$ of $0^{\circ}, \pm 45^{\circ}$ and $90^{\circ}$ layers) for the skin and different layup for spars and stiffeners [17] was carried out. Buckling analysis of the stiffened composite skin panels was carried out by employing the finite strip method in Engineering Science Data Unit (ESDU) 03001 [14], together with the practical design rules given by Niu [15]. As a result, the upper skin panel thickness varies from $22 \mathrm{~mm}$ inboard to $3 \mathrm{~mm}$ at the wingtip, as shown in Figure 5a. The buckling load factors are between 1.05 and 1.5. The lower skin thickness varies from $17 \mathrm{~mm}$ inboard to $3 \mathrm{~mm}$ at the wingtip with a failure index below 0.8 under an ultimate load factor of 3.75 along the wing span. Taking the outer wing box structure as an example, the wing component mass breakdown of a total mass of $1436 \mathrm{~kg}$ is shown in Figure $5 \mathrm{~b}$.

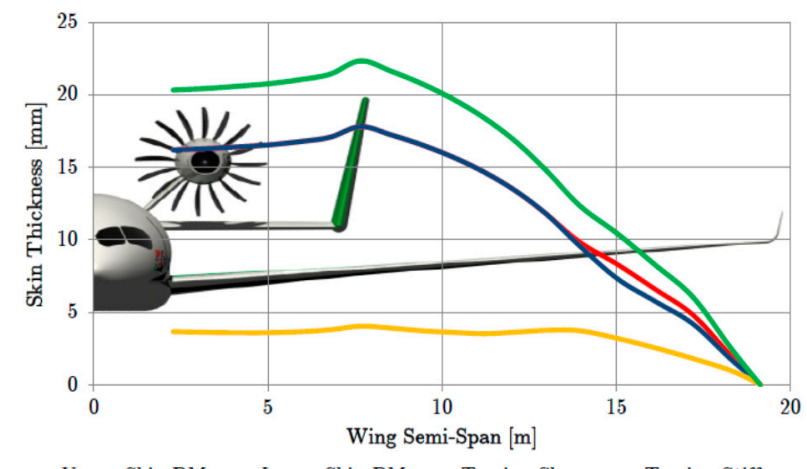

(a)

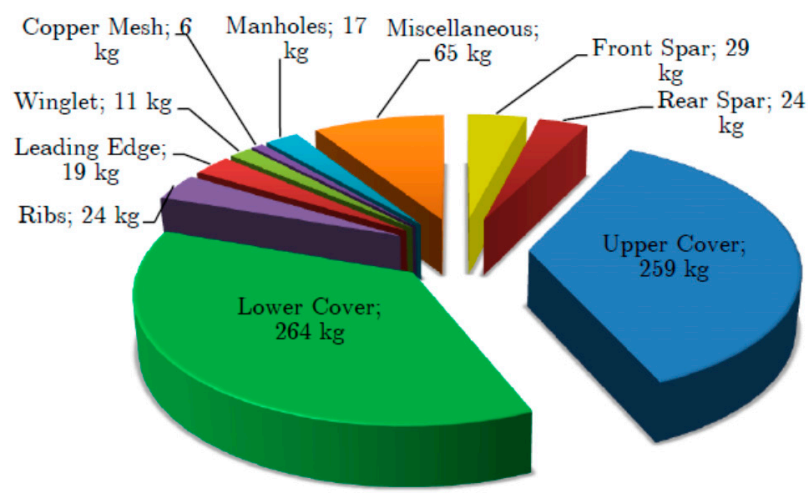

(b)

Figure 5. (a) Skin cover thickness and (b) mass breakdown of outer wing box from the initial design.

\subsection{Structural FE Model and Stress Analysis}

Based on the initial design, the FE model of the composite wing structure was created, using Patran/Nastran. In the FE model, the skins, ribs and spar webs are modelled using 18,500 shell elements for the outer wing; the stringers and spar capes are modelled by using beam elements. The FE analysis results show a maximum displacement of $1.78 \mathrm{~m}$ at the wingtip under the static ultimate load, as shown in Figure 3. The associated failure index (FI) of the upper skin panel is shown in Figure 6a, and the strain distribution of the upper and lower skin covers is shown in Figure $6 \mathrm{~b}$.

The results show that the maximum FI is less than 1.0 and the strain less than $3500 \mu \varepsilon$ (micro-strain) in all regions of the wing box. It is observed that the most critical FI and strain close to the limit occur only at the wing root, especially around the rear spar, where high stress concentration exists due to the clamped boundary condition at discrete nodes. The results indicate that the design of the wing structure has met the strength and buckling requirements. 


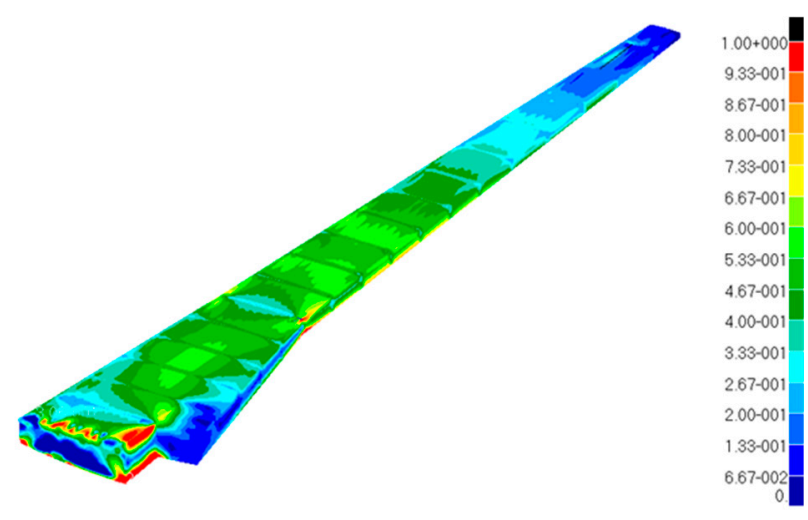

(a)

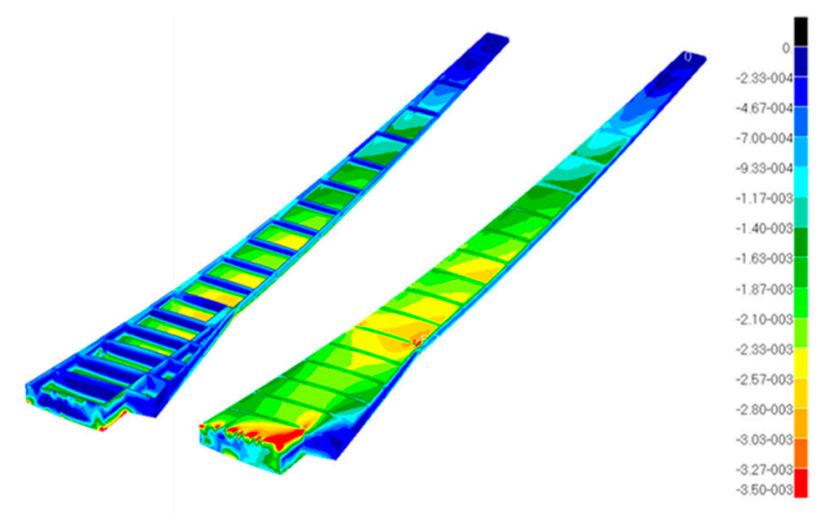

(b)

Figure 6. (a) The failure index (FI) results of the upper skin; and (b) strain plot of the lower and upper skins of the wing.

\subsection{Aeroelastic and Gust Response Analysis}

Based on the FE model, modal analysis was carried out as part of the aeroelastic analysis procedure. The first five frequencies in both maximum take-off mass (MTOM) and operational empty fuel mass (OEM) are listed in Table 3. Due to the inertia effect of the fuel in the wing box, the frequencies in MTOM are smaller than that in the OEM case. In the subsequent aeroelastic analysis, the five dominant bending and torsion modes were considered in this preliminary design stage. The results are presented in the $V-g$ plot, shown in Figure 7a, indicating that the flutter speed is $V_{\mathrm{f}}=580 \mathrm{~m} / \mathrm{s}$ for MTOM and $V_{\mathrm{f}}=820 \mathrm{~m} / \mathrm{s}$ for the OEM case, which keeps a large safety margin from the limit of $283 \mathrm{~m} / \mathrm{s}$ according to the $\mathrm{CS}-25$ regulation.

Table 3. The first a few frequencies in the full fuel and empty fuel cases.

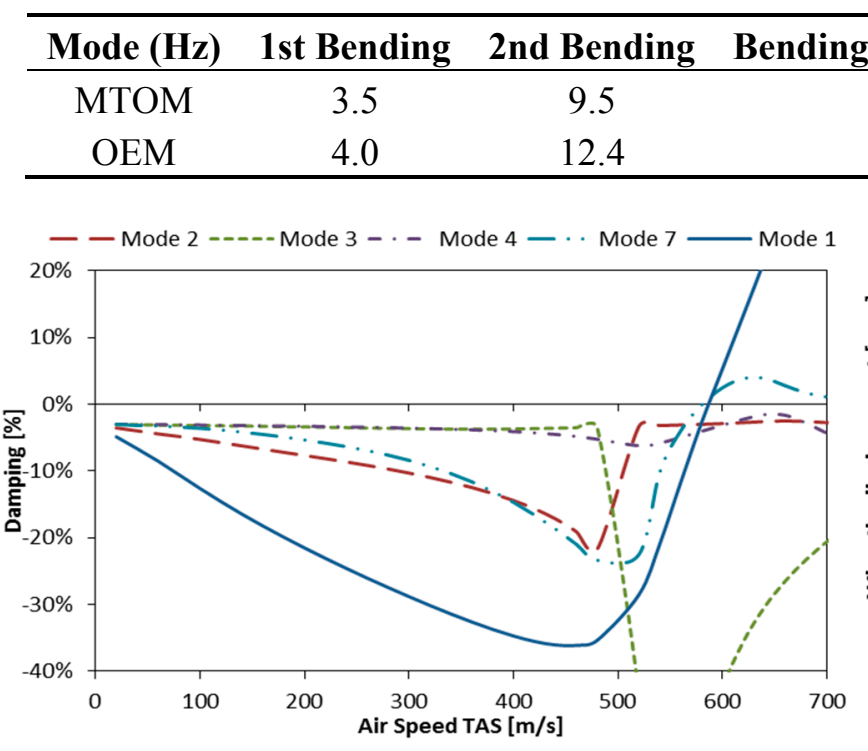

(a)

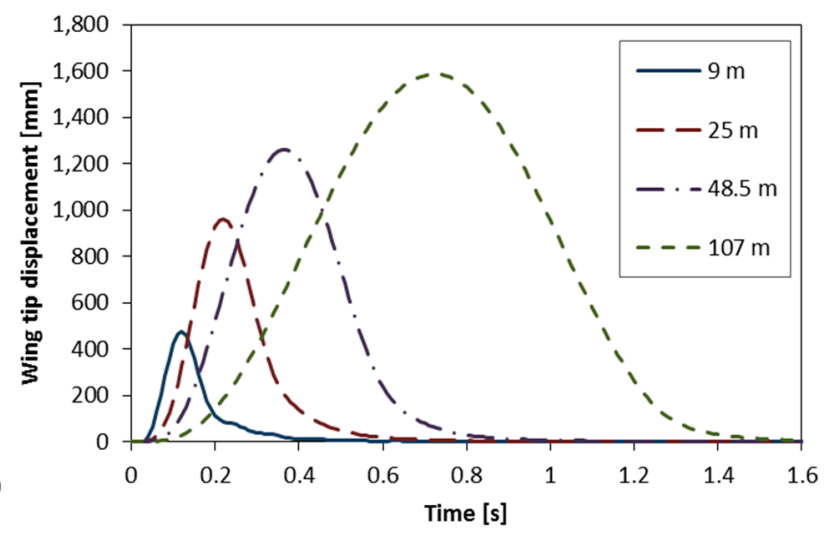

(b)

Figure 7. (a) The flutter $V-g$ plot for MTOM and (b) gust response at four gust gradients in the MTOM case. 
In the gust response analysis, four different values of gust gradient distance were selected from the lowest $9 \mathrm{~m}$ to the highest $107 \mathrm{~m}$, including the typical value $12.5 c=48.5 \mathrm{~m}$, according to the CS-25 specified range. The standard structural damping coefficient 0.03 was taken into account [22] in the model as expressed in Equation (1). Corresponding to the four gust gradient distances, the flight profile alleviation factor $F_{\mathrm{g}}=0.974$ is obtained from Equation (4), and the design gust velocity and gust equivalent frequencies in the most critical case at sea level and cruise speed were calculated and listed in Table 4.

Table 4. The design gust velocity and frequency against the gust gradient distances.

\begin{tabular}{ccccc}
\hline Gust Gradient Distance $\boldsymbol{H}(\mathbf{m})$ & $\mathbf{9 . 0}$ & $\mathbf{2 5}$ & $\mathbf{1 2 . 5} \overline{\boldsymbol{c}}=\mathbf{4 8 . 5}$ & $\mathbf{1 0 7 . 0}$ \\
\hline Design gust velocity $U_{\mathrm{ds}}(\mathrm{m} / \mathrm{s})$ & 6.63 & 7.86 & 8.77 & 10.01 \\
Gust frequency $(\mathrm{Hz})$ & 9.72 & 3.50 & 1.80 & 0.80 \\
\hline
\end{tabular}

It is noted from Tables 3 and 4 that the gust load falls into the frequency range of the first two bending modes of the wing structure in the MTOM case and the first mode in the OEM case. The gust in the specified range is likely to cause a large gust response at the structure's natural frequency. For example, the gust gradient $H=25 \mathrm{~m}$ and frequency $3.5 \mathrm{~Hz}$ are identical to the first bending mode of the wing in the MTOM case, which could be critical. Taking the MTOM case at sea level, the gust response in terms of the wingtip deflection has been calculated for all four gust gradients and frequencies listed in Table 4. From the results, as shown in Figure 7b, it is noted, however, that the maximum wingtip deflection of $1.59 \mathrm{~m}$ actually corresponds to the gust gradient $H=107 \mathrm{~m}$ associated with the greatest gust velocity. The gust response is in addition to the static deflection in the $1 g$ level flight. Comparing with the $1.78 \mathrm{~m}$ wingtip deflection and $3500 \mu \varepsilon$ (micro-strain) under the ultimate load, this result indicates that the gust load reaches nearly $90 \%$ of the most critical ultimate load. In addition to the lifting force in trimmed level flight, the maximum aerodynamic force on the wing would exceed the ultimate load by $15.7 \%$. This raises a serious concern for the structural integrity. The problem could be resolved either by the cost of the weight penalty or a load alleviation technology.

The gust response results for the four gust gradients $H$ in different altitudes and cruise speeds $V_{\mathrm{C}}$ and the design speed for maximum gust intensity $V_{\mathrm{B}}$ were also calculated. A summary of the maximum wingtip displacements is listed in Table 5. From Tables 4 and 5 and Figure $7 \mathrm{~b}$, it is noted that the most critical condition for the aircraft in MTOM is the gust gradient $H=107 \mathrm{~m}$ at $V_{\mathrm{C}}$ and sea level corresponding to the maximum gust velocity $U_{\mathrm{ds}}$ and response.

Table 5. The gust response in different flight conditions.

\begin{tabular}{|c|c|c|c|c|c|c|}
\hline \multirow{2}{*}{ Altitude } & \multirow{2}{*}{ Airspeed } & \multirow{2}{*}{ Case } & \multicolumn{4}{|c|}{ Gust Response (mm) } \\
\hline & & & $H=9 \mathrm{~m}$ & $H=25 \mathrm{~m}$ & $H=48.5 \mathrm{~m}$ & $H=107 \mathrm{~m}$ \\
\hline \multirow{4}{*}{ Sea level } & \multirow{2}{*}{$V_{\mathrm{B}}$} & MTOM & 466 & 677 & 968 & 1,179 \\
\hline & & OEM & 484 & 647 & 867 & 1,037 \\
\hline & \multirow{2}{*}{$V_{\mathrm{C}}$} & MTOM & 474 & 960 & 1,261 & 1,586 \\
\hline & & OEM & 474 & 959 & 1,261 & 1,587 \\
\hline \multirow{2}{*}{ Cruise altitude } & \multirow{2}{*}{$V_{\mathrm{C}}$} & MTOM & 216 & 465 & 614 & 776 \\
\hline & & OEM & 217 & 464 & 614 & 776 \\
\hline
\end{tabular}




\section{The PTWT Design and Gust Response}

\subsection{The PTWT Key Parameters and Influence on Gust Response}

The PTWT is a separate wing segment mounted at the wingtip through a shaft and torque spring connected to the wing front spar, as illustrated in Figure 8a. For the shaft located in front of the aerodynamic centre, the gust-induced aerodynamic force will cause the PTWT twist nose to be down, as illustrated in Figure 8a. This twist produces a negative AoA and a negative aerodynamic force on the PTWT that leads to gust alleviation of the wing. There are five key design parameters that affect the PTWT design and performance, the dimension, the shaft position in the chordwise direction, the torque spring stiffness and the mass and location of the centre of gravity (CG). In this current study, a small PTWT of $1.13 \mathrm{~m}$ in the same length as the wingtip chord was taken. The rest of the three parameters will be determined subject to the design constraints and, in particular, the PTWT twist angle and aeroelastic stability.

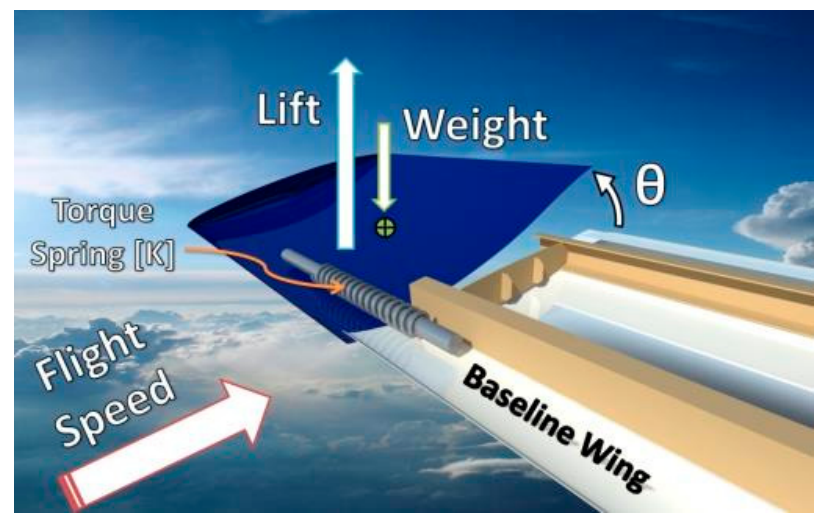

(a)

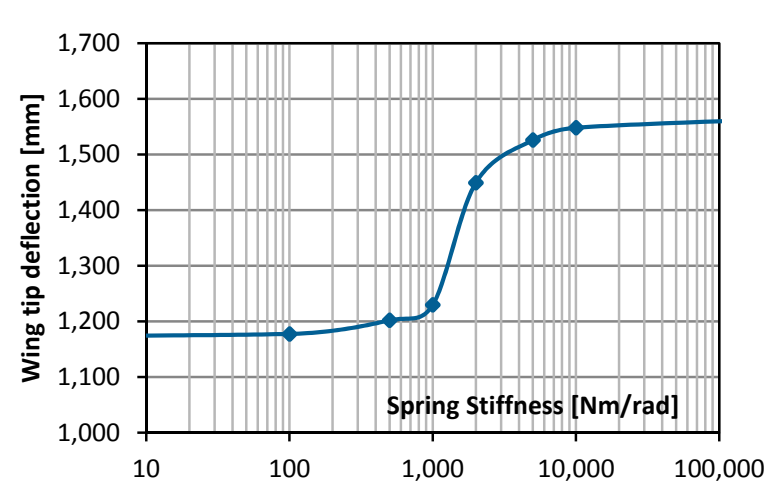

(b)

Figure 8. (a) The PTWT and (b) the wing gust response for a range of torsion stiffness.

The basic requirement for the torque spring is set to be stiff enough to maintain the designed aerodynamic angle of $3.7^{\circ}$ under the $1 g$ level flight lift in cruise. Under extra lift due to gust, the maximum twist angle of the PTWT is limited to $-10^{\circ}$ to avoid stall. The shaft working as the PTWT front spar and also the spring supporter is of adequate bending and torsion stiffness.

In the previous study on a similar passive gust alleviation device for a flying wing aircraft [7], the torque spring stiffness between 10 and $40 \mathrm{kNm}$ and the shaft location in the range of $5 \%-35 \%$ chord was evaluated. It was noted that the required spring stiffness was greater due to the larger wing span of $63 \mathrm{~m}$ and the longer device of $1.85 \mathrm{~m}$ compared with the aircraft in the current study. In the previous study, the shaft location was set at $5 \%$ chord from the leading edge for the maximum gust alleviation effect.

In the current PTWT design, the shaft connected to the front spar was located at $10 \%$ chord from the leading edge. The spring stiffness was considered in the range of $0.1-10 \mathrm{kNm} / \mathrm{rad}$. The PTWT is made of sandwich composite skin reinforced by the spar and has a total mass of $30 \mathrm{~kg}$. Since the PTWT mass is mainly in the front of the mid-chord dominated by the shaft and spring, its CG is located at $5 \%$ chord behind the shaft (15\% from leading edge). Based on the initial design, an FE model of the PTWT was created at the wingtip to replace the original fixed wingtip. 
In the gust response analysis, the control surfaces were locked in neutral position. The gust response of the aircraft in terms of wingtip deflection was calculated in the most critical condition within a specified range of PTWT spring stiffness to determine the minimum stiffness. For the case of the wing clamped at the root, the gust response results are presented in Figure 8b. Within the range of spring stiffness from $K=0.1$ to $10 \mathrm{kNm} / \mathrm{rad}$, the PTWT torsional frequency increases from 0.034 to $0.173 \mathrm{~Hz}$. This result indicates that coupling can be avoided between the PTWT torsion mode and the first bending mode of the wing. Figure $8 \mathrm{~b}$ also shows that the hardest spring of $10 \mathrm{kNm} / \mathrm{rad}$ would result in a gust response of $1.57 \mathrm{~m}$ of wingtip deflection, which is close to the result for the baseline aircraft, as shown in Figure $7 \mathrm{~b}$. The minimum gust response of $1.18 \mathrm{~m}$ deflection is associated with the softest spring with the PTWT twist angle restricted to $-10^{\circ}$.

The aerodynamic model of the PTWT was also created as a separate surface at the wingtip in the gust response analysis. Figure $8 \mathrm{~b}$ shows that the gust response is most sensitive to the spring stiffness between 1 and $2 \mathrm{kNm} / \mathrm{rad}$. For a stiffness of $2 \mathrm{kNm} / \mathrm{rad}$ or greater, the PTWT twist angle in response to the specified gust is below $-5^{\circ}$. In this case, the gust alleviation can reach $7.5 \%$ with the maximum wingtip deflection reduced to 1443 from $1560 \mathrm{~mm}$ for the baseline aircraft, as shown in Figure $7 \mathrm{~b}$. If the minimum stiffness of $0.1 \mathrm{kNm} / \mathrm{rad}$ were taken, the PTWT twist angle in response to the gust would reach $-10^{\circ}$. In this case, $25 \%$ gust alleviation can be obtained with the wingtip deflection reduced from 1560 to $1170 \mathrm{~mm}$. To keep the PTWT in neutral position at cruise speed, however, the minimum stiffness of $1 \mathrm{kNm} / \mathrm{rad}$ is required and, therefore, used in the PTWT design. The spring stiffness of $1 \mathrm{kNm} / \mathrm{rad}$ can be obtained by using a steel helical spring of five coils with coil diameter of $20 \mathrm{~mm}$ and a spring diameter of $100 \mathrm{~mm}$.

To ensure that the torsional stiffness and mass satisfy the aeroelastic constraint, flutter analysis of the wing with PTWT using different parameters was performed. Figure 9a,b shows the results of flutter speed variation within a range of stiffness and mass, respectively. A critical flutter speed of $283 \mathrm{~m} / \mathrm{s}$, which is $15 \%$ greater than the dive speed, is marked to indicate the aeroelastic design requirement according to CS-25. The results show that the flutter speed is $300 \mathrm{~m} / \mathrm{s}$ for the wing with the PTWT of $30 \mathrm{~kg}$ mounted on the shaft with a spring stiffness of $1 \mathrm{kNm} / \mathrm{rad}$. This PTWT design satisfies the aeroelastic stability requirement. Figure $9 \mathrm{a}, \mathrm{b}$ also indicates that the flutter speed will be increased by either increasing the torsional stiffness or reducing the mass of the PTWT based on the current design.

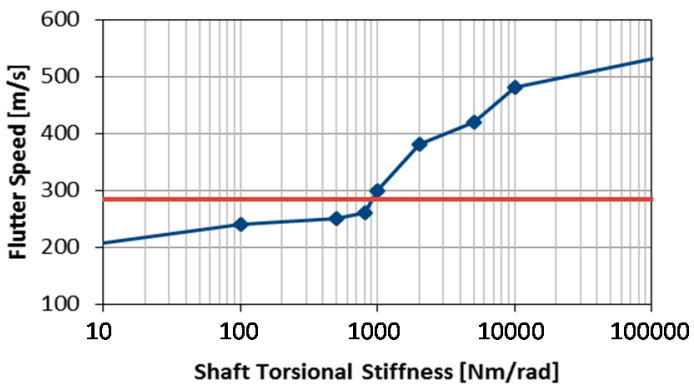

(a)

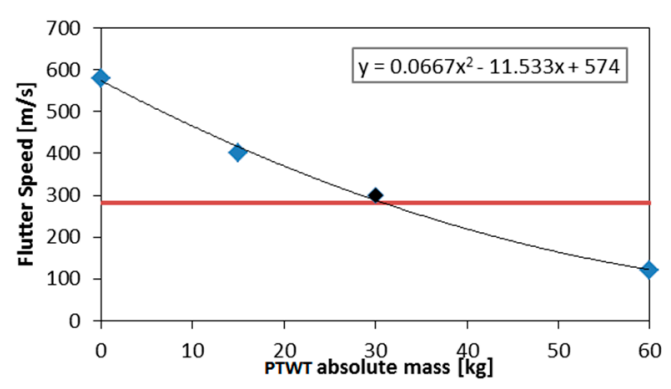

(b)

Figure 9. (a) The wing flutter speed $v s$. the PTWT shaft torsion stiffness and (b) the mass. 
Based on the PTWT design with a spring stiffness of $1 \mathrm{kNm} / \mathrm{rad}$, the gust response has been calculated in the four gust gradient cases and different flight conditions. The results of the gust response reduction of the wing achieved by employing the PTWT are listed in Table 6. From the results, it is noted that the PTWT is generally more effective at larger gust gradients or lower gust frequencies.

Table 6. The gust alleviation achieved by the PTWT in different flight conditions.

\begin{tabular}{cccccc}
\hline Altitude & Airspeed & $\boldsymbol{H}=\mathbf{9} \mathbf{~ m}$ & $\boldsymbol{H}=\mathbf{2 5} \mathbf{~ m}$ & $\boldsymbol{H}=\mathbf{4 8 . 5} \mathbf{~ m}$ & $\boldsymbol{H}=\mathbf{1 0 7} \mathbf{~ m}$ \\
\hline \multirow{2}{*}{ Sea level } & $V_{\mathrm{B}}$ & $-7.7 \%$ & $-9.7 \%$ & $-23.4 \%$ & $-22.0 \%$ \\
\cline { 2 - 6 } & $V_{\mathrm{C}}$ & $-5.1 \%$ & $-12.6 \%$ & $-21.2 \%$ & $-9.8 \%$ \\
\hline Cruise altitude & $V_{\mathrm{C}}$ & $-6.5 \%$ & $-10.5 \%$ & $-18.4 \%$ & $-24.3 \%$ \\
\hline
\end{tabular}

\subsection{Gust Response of the Whole Aircraft}

In the above study, the wing was clamped at the root, so that the analysis was focused on the PTWT effectiveness during the wing loading without the aircraft body motion. In such a case, the gust response is relatively large and overestimated compared to real life. To calculate the gust response of the whole aircraft, the fuselage and tail are modelled as a rigid body with free motion. For symmetric motion, the degrees of freedom of the aircraft model are set free in transverse and pitching directions. The gust response was measured in terms of displacement at the aircraft $\mathrm{CG}$ and the wingtip deflection relative to the CG. Firstly, the gust response of the baseline aircraft was calculated in the most critical gust case, as described in the previous section, with the result shown in Figure 10.

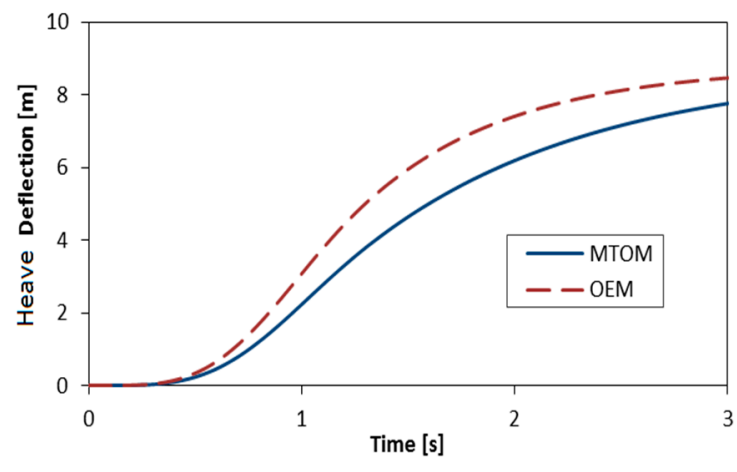

(a)

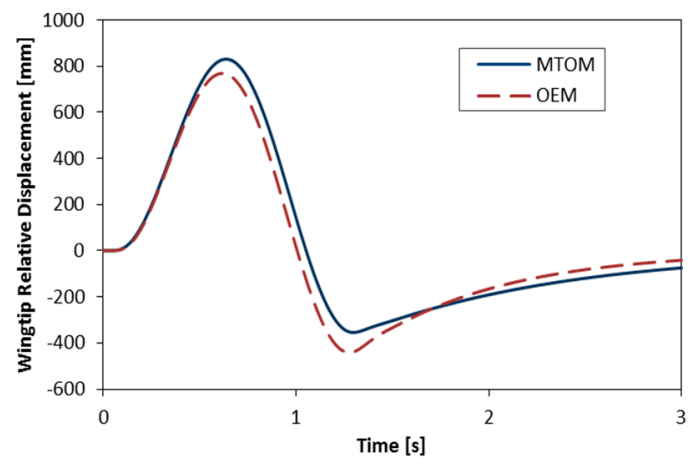

(b)

Figure 10. (a) Gust response at the centre of gravity $(\mathrm{CG})$ and (b) the wingtip deflection of the baseline aircraft.

Comparing with the previous results of the wing alone absorbing all of the gust energy, as shown in Figure $7 \mathrm{~b}$, the gust load on the wing was largely reduced with the wingtip deflection reduced by $48 \%$ from 1.59 to $0.82 \mathrm{~m}$, as shown in Figure 10b. This is because the gust energy was absorbed by the wing elastic deformation and also the potential energy of the aircraft with an upward heave motion over $8 \mathrm{~m}$, as shown in Figure 10a. Comparing with the wingtip deflection and strain under the static ultimate load, this result indicates that the gust load in real lift actually reaches $46 \%$ of the ultimate load and puts the structural integrity at risk.

When the PTWT was employed, the gust-induced wingtip deflection relative to the CG was calculated and is shown in Figure 11a. In comparison with the baseline results in Figure 10, it can be 
seen that a significant reduction of wingtip deflection by $21.2 \%$ from 0.83 to $0.65 \mathrm{~m}$ has been achieved. Figure $11 \mathrm{~b}$ shows the elastic twist angle of the wing and the PTWT twist angle reaching almost $-9^{\circ}$ relative to the wing in response to the gust load.

Based on the analysis, the bending moment at the wing root was also reduced significantly by $10.6 \%$. A summary of the aircraft gust alleviation results at sea level for both the MTOM and OEM cases by employing the PTWT in the same most critical gust $H=107 \mathrm{~m}$, as described in the previous section, is presented in Table 7. The results indicate that the gust-induced extra load on the wing can be reduced from $46 \%$ of the ultimate load (1.75 g) to $36.5 \%$ (1.39 g) by employing the PTWT. Comparing with the baseline aircraft where the maximum load in the most critical gust exceeded the design ultimate load by $15.7 \%$, the PTWT has reduced the maximum aerodynamic load below the ultimate load.

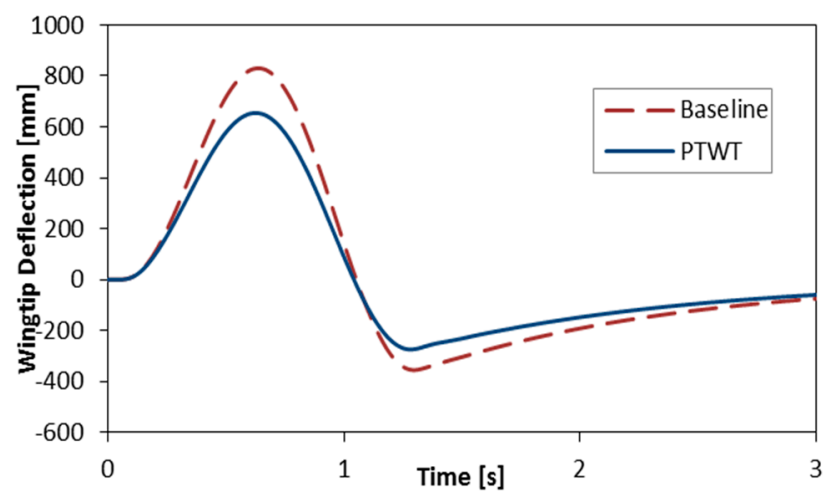

(a)

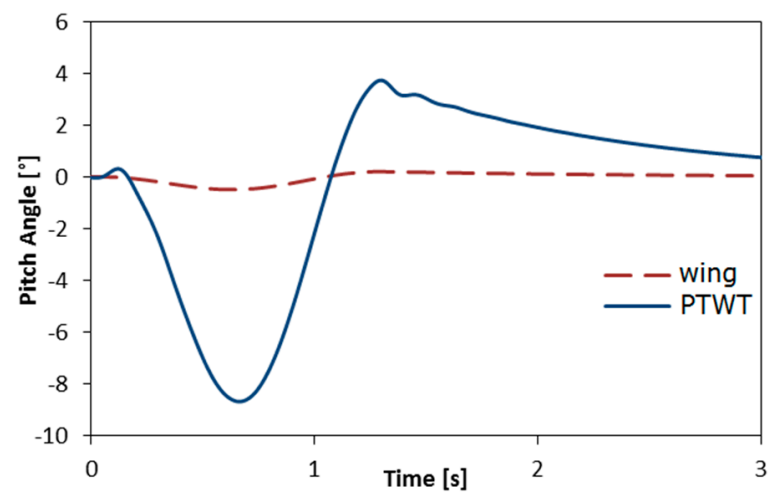

(b)

Figure 11. (a) The wingtip deflection with and without PTWT and (b) the wing and PTWT twist angle.

Table 7. The gust response reduction with the PTWT against the baseline aircraft.

\begin{tabular}{cccc}
\hline Case & Normal Acceleration at CG & Bending Moment & Wing Deflection \\
\hline MTOM & $-2.4 \%$ & $-10.6 \%$ & $-21.2 \%$ \\
OEM & $-3.2 \%$ & $-14.4 \%$ & $-20.6 \%$ \\
\hline
\end{tabular}

\subsection{The PTWT Influence on the Flight Manoeuvre Performance}

Due to the nature of the PTWT in gust alleviation, it could have a negative influence on the flight performance when manoeuvring is required by operating the control surfaces. An investigation was carried out on the evaluation of the aircraft symmetric and unsymmetrical manoeuvrability with the PTWT unlocked.

In the symmetric manoeuvre simulation, a step input from the aircraft elevator was considered. In response to the elevator rotation, the aircraft would produce an incidence change that can be expressed by an exponential decay time function $\alpha(t)=1-e^{-\lambda t}$, where a decay constant $\lambda=4$ was taken [20]. For this aircraft, the angle of incidence converged to $5^{\circ}$ after $1 \mathrm{~s}$ time associated with a steady pitch rate, as shown in Figure 12a. The corresponding variation of the PTWT twist angle over $4 \mathrm{~s}$ period is shown in Figure $12 \mathrm{~b}$. 


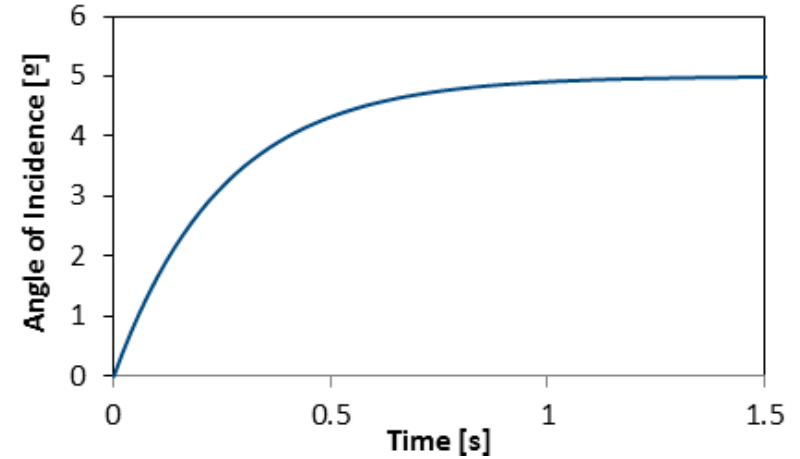

(a)

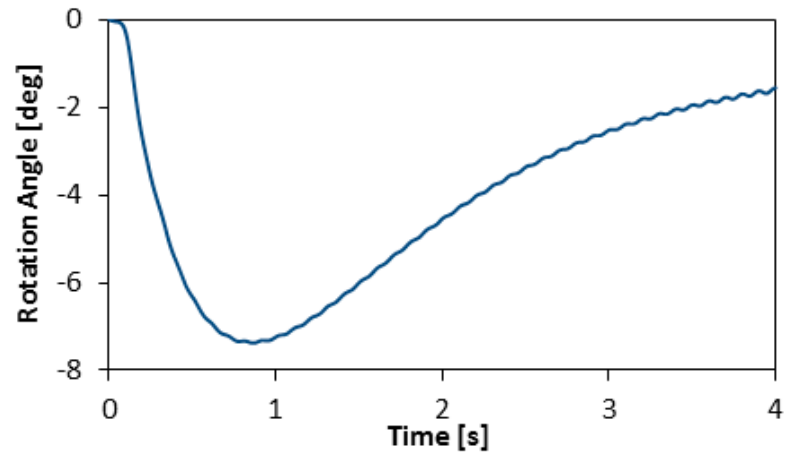

(b)

Figure 12. (a) The aircraft incidence and (b) the PTWT twist angle in response to an elevator step input.

In response to the elevator input and the PTWT reaction, the normal velocity of the aircraft in MTOM increased from the level flight speed and converged to a stable value, as shown in Figure 13a. Comparing with the baseline aircraft, the normal velocity was reduced by $1.7 \%$ due to the PTWT-induced drag. The corresponding reduction of acceleration was $2.7 \%$ only. Figure $13 \mathrm{~b}$ shows that the aircraft heave motion as a result of the incidence change was reduced by only $3 \%$ due to the PTWT. The normal velocity converged to a constant value, and the heave motion kept increasing, because no reverse elevator input was set to recover the aircraft status. The results indicate that the PTWT influence on the symmetric manoeuvrability is negligible. This is mainly because the PTWT twist angle, as shown in Figure 12b, has little influence on the increase of the aircraft incidence and lift due to the elevator action, as shown in Figure 12a.

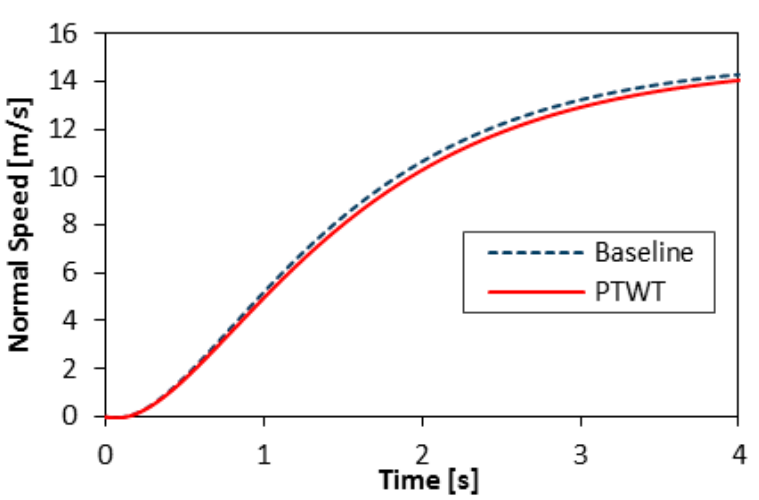

(a)

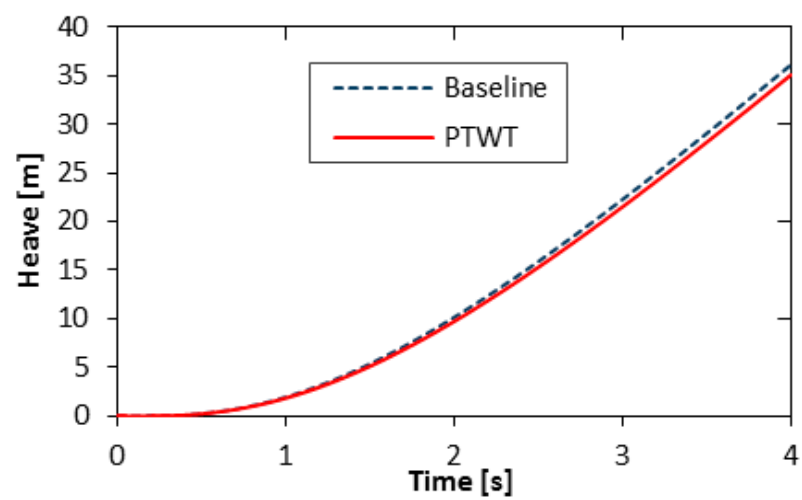

(b)

Figure 13. (a) The normal velocity and (b) heave motion of the aircraft with and without the PTWT.

A summary of the PTWT influence on the symmetric manoeuvring measured as the percentage reduction of the aircraft normal acceleration, velocity and movement is listed in Table 8.

Table 8. The PTWT influence on the aircraft symmetric manoeuvring.

\begin{tabular}{ccc}
\hline Parameter & MTOM & OEM \\
\hline Max normal acceleration & $-2.7 \%$ & $-2.6 \%$ \\
Vertical speed after 4 s & $-1.7 \%$ & $-0.6 \%$ \\
Heave after 4 s & $-2.9 \%$ & $-1.6 \%$ \\
\hline
\end{tabular}


In the unsymmetrical rolling manoeuvre, an input aileron rotation at a rate of $6 \% \mathrm{~s}$ was considered in an exponential time function, as shown in Figure 14a. In response to the aileron rotation, the PTWT had a twist angle up to $-6^{\circ}$ in the opposite direction, as shown in Figure 14a. Due to the PTWT effect, the rolling moment of the aircraft is reduced by $20.5 \%$ compared with the baseline aircraft, as shown in Figure $14 \mathrm{~b}$. Consequently, the roll rate and the resulting roll angle were reduced by $11.6 \%$ and $10.6 \%$, respectively, as shown in Figure 15. It is noted that the significant reduction of the roll moment is due to the negative effect of PTWT on both wings. If the PTWT nose-up rotation were restricted, the PTWT influence on the wing with the aileron rotating upward would be eliminated and the influence on the aircraft rolling moment would be reduced significantly.

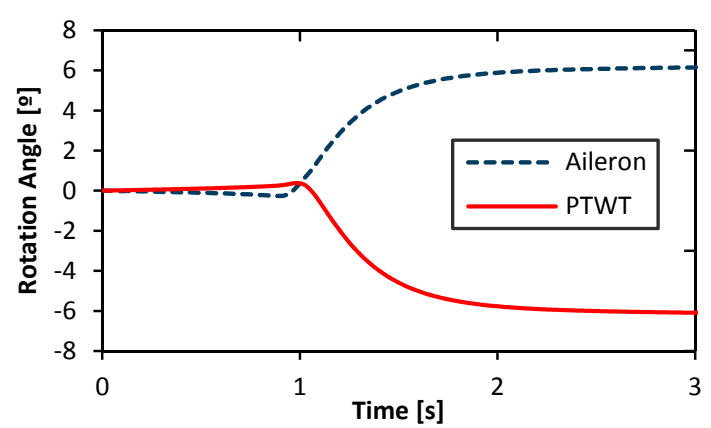

(a)

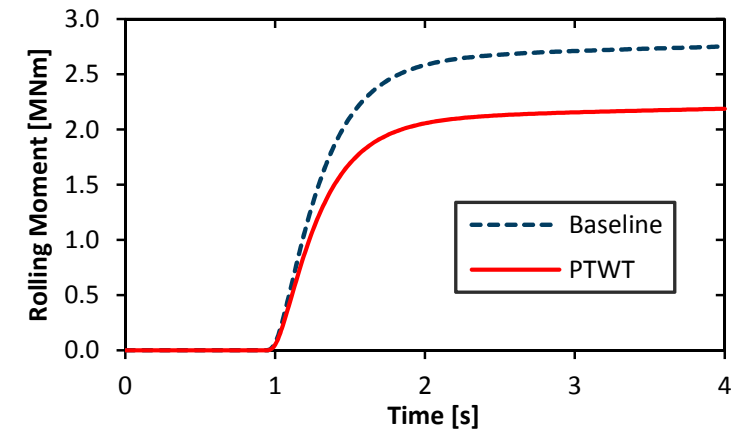

(b)

Figure 14. (a) The input aileron rotation angle and (b) the corresponding rolling moment of the aircraft.

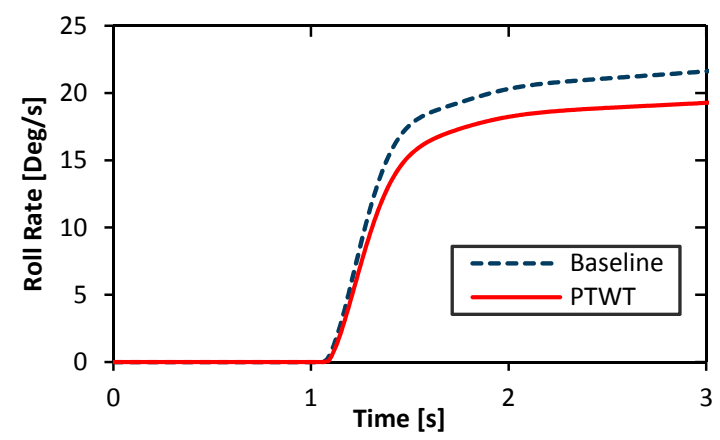

(a)

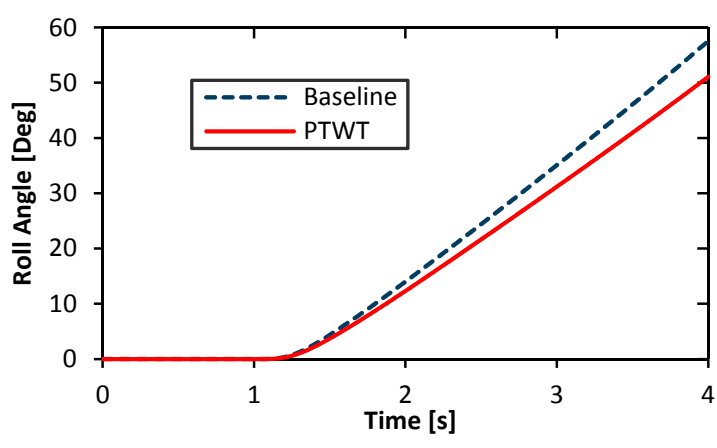

(b)

Figure 15. (a) The roll rate and (b) roll angle of the aircraft with and without the PTWT.

In addition, the associated roll acceleration was reduced by $13 \%$. A summary of the PTWT influence on the unsymmetrical manoeuvring measured as the percentage reduction of the aircraft roll acceleration, rate and angle after four seconds is listed in Table 9.

Table 9. The PTWT influence on the aircraft unsymmetrical manoeuvring.

\begin{tabular}{ccc}
\hline Parameter & MTOM & OEM \\
\hline Maximum roll acceleration & $-13.5 \%$ & $-13.6 \%$ \\
Roll rate after 4 s & $-11.6 \%$ & $-11.8 \%$ \\
Roll angle after 4 s & $-10.6 \%$ & $-10.8 \%$ \\
\hline
\end{tabular}




\section{Conclusions}

The feasibility and effectiveness of employing a passive twist wingtip (PTWT) for gust alleviation has been evaluated through a case study of a 200 -seater passenger aircraft with a high aspect ratio wing in this investigation. The baseline airframe, especially the composite wing structure, has been modelled and analysed at the detailed design level subject to the design criteria in line with CS-25. In the most critical gust load case, the maximum aerodynamic load on the wing can exceed the design ultimate load by $15.7 \%$ and cause concern for the structural integrity. In the PTWT design, the key parameters were determined based on the gust response and flutter analysis of the wing to achieve maximum effectiveness and aeroelastic stability.

The results show that significant gust response alleviation can be achieved by employing the PTWT in the whole range of gust gradients specified in the airworthiness standards. In the most critical case, the gust-induced wingtip deflection and bending moment at the wing root can be reduced by $21 \%$ and $11 \%$, respectively. Consequently, the maximum load, including the worst gust load, on the wing can be reduced below the design ultimate load by employing the PTWT.

The PTWT influence on the symmetric manoeuvring of the aircraft in terms of normal velocity and heave motion is negligible. However, the PTWT influence on unsymmetrical manoeuvring of the aircraft raises a concern with the roll moment and roll rate reduced by $20.5 \%$ and $12 \%$, respectively. Since the PTWT reduces the rolling control effectiveness, it makes the system more conservative rather than detrimental. To offset the negative effect, the input aileron rotation rate or angle need to be increased to enhance the performance. Alternative measures, such as a PTWT locking system, which is not an ideal option, could also be used during manoeuvring operation. The investigation has shown that the PTWT is a reliable and effective means for gust alleviation and has potential application for such a large civil aircraft.

\section{Notation}

al Lift curve slope of the wing

c Wing mean chord

$\left[D_{\mathrm{hh}}\right] \quad$ Generalized damping matrix

$E_{1} / E_{2} \quad$ Ply modulus in fiber/off-fiber direction

$F_{\mathrm{g}} \quad$ Flight profile alleviation factor

$G_{12} \quad$ Shear modulus of the ply

$H \quad$ Gust gradient distance

$k \quad$ Reduced frequency

$K \quad$ Spring stiffness of the PTWT

[Khh $\quad$ Generalized stiffness matrix

$L \quad$ Aerodynamic lift force

$\left\{L_{\mathrm{G}}\right\} \quad$ Gust induced aerodynamic force vector

$\{L \mathrm{hh}\} \quad$ Unsteady aerodynamic force vector

[Mhl Generalized mass matrix

$\{q \mathrm{~h}\} \quad$ Generalized coordinate vector 
$\left\{Q_{\mathrm{G}}\right\} \quad$ Generalized aerodynamic force due to gust

[ $\left.Q \mathrm{hh}^{\mathrm{i}}\right] \quad$ Generalized unsteady aerodynamic matric (imaginary part)

$\left[Q_{\mathrm{hh}}{ }^{\mathrm{R}}\right]$ Generalized unsteady aerodynamic matric (real part)

$p \quad$ Static pressure

$s \quad$ Reference area of the wing

$S \quad$ Shear strength of ply

$U \quad$ Gust velocity

$U_{\mathrm{ds}} \quad$ Design gust velocity

$U_{\text {ref }} \quad$ Reference gust velocity

$V \quad$ Airspeed

$V_{\mathrm{B}} \quad$ Design speed for maximum gust velocity

$V_{\mathrm{C}} \quad$ Cruise airspeed

$V_{\mathrm{D}} \quad$ Dive airspeed

$V_{\mathrm{f}} \quad$ Flutter airspeed

$X_{\mathrm{t}} / X_{\mathrm{c}} \quad$ Tension/compression strength of ply in fiber direction

$Y_{\mathrm{t}} / Y_{\mathrm{c}} \quad$ Tension/compression strength of ply in off-fiber direction

$Z_{\mathrm{mo}} \quad$ Maximum operating altitude

$\lambda \quad$ Decay constant

$\mu \quad$ Mass parameter

$\rho \quad$ Air density

$v_{12} \quad$ Poisson's ration of ply

$\omega \quad$ Gust frequency

[Ф] Modal matrix of the structure in special coordinates

\section{Abbreviations}

AoA Angle of attack

CFD Computational Fluid Dynamics

CG Center of gravity

FE Finite element

FI Failure Index

MLM Maximum landing mass

MTOM Maximum take-off mass

MZFM Maximum zero fuel mass

OEM Operating empty mass

PTWP Passive twist wing tip (device)

\section{Acknowledgments}

The authors acknowledge the financial contribution and support for the projects funded by European Office of Aerospace Research and Development/US Air Force Research Laboratory (EOARD/AFRL) and Chinese Natural Science Funding Council (NSFC 11302027). 


\section{Author Contributions}

Shijun Guo initiated the project and provided technical supervision. He analysed the results and wrote the main part of the paper; Jaime Espinosa De Los Monteros drafted the manuscript and carried out the modelling and analysis work together with Ying Liu.

\section{Conflicts of Interest}

The authors declare no conflict of interest.

\section{References}

1. Baldelli, D.H.; Ohta, H.; Nitta, K. Gust load alleviation of an aeroelastic wing model. Trans. Jpn. Soc. Aeronaut. Spacial Sci. 1993, 36, 125-142.

2. Honlinger, H.; Zimmermann, H.; Sensburg, O.; Becker, J. Structural Aspects of Active Control Technology; AGARD Flight Mechanics Panel Symposium: Turin, Italy, 1995.

3. Guo, S.; Cheung, W.; Banerjee, J.R.; Butlar, R. Gust alleviation and flutter suppression of an optimized composite wing. In Proceedings of the International Forum on Aeroelasticity and Structural Dynamics, Manchester, UK, 24-26 June 1995; p. 41.

4. Moulin, B.; Karpel, M. Gust loads alleviation using special control surfaces. J. Aircr. 2007, 44, 17-25.

5. Dillsaver, M.J.; Cesnik, C.E.S. Gust load alleviation control for very flexible aircraft. In Proceedings of the AIAA Atmospheric Flight Mechanics Conference, Portland, OR, USA, 8-11 August 2011.

6. Britt, R.; Jacobson, S.; Arthurs, T. Aeroservoelastic Analysis of the B-2 Bomber. J. Aircr. 2000, 37, 745-752.

7. Guo, S.; Fu, Q.; Sensburg, O.K. Optimal design of a passive gust alleviation device for a flying wing aircraft. In Proceedings of the 12th AIAA ATIO/14th AIAA/ISSMO MAO Conference, Session MAO-25, Indianapolis, IN, USA, 17-19 September 2012.

8. Miller, S.; Vio, G.A.; Cooper, J.E.; Sensburg, O.K. Optimisation of a scaled sensorcraft model with passive gust alleviation. In Proceedings of the 12th AIAA/ISSMO Multidisciplinary Analysis and Optimization Conference, MAO, Victoria, BC, Canada, 10-12 September 2008.

9. Vartio, E.; Shimko, A.; Tilmann, C.P.; Flick, P.M. Structural Modal Control and Gust Load Alleviation for a SensorCraft Concept. In Proceedings of the 46th AIAA/ASME/ASCE/AHS/ASC Structures, Structural Dynamics \& Materials Conference, Austin, TX, USA, 18-21 April 2005.

10. Tilmann, C.P.; Flick, P.M.; Martin, C.A.; Love, M.H. High-altitude long endurance technologies for sensorcraft, RTO Paper MP-104-P-26. In Proceedings of the RTO AVT-099 Symposium on Novel and Emerging Vehicle and Vehicle Technology Concepts, Brussels, Belgium, 7-11 April 2003.

11. Reich, G.; Raveh, D.; Zink, P. Application of Active Aeroelastic Wing Technology to a Joined-Wing SensorCraft. In Proceedings of the AIAA Paper 2002-1633 43rd AIAA/ASME/ASCE/AHS/ASC Structures, Structural Dynamics, and Materials Conference, Denver, CO, USA, 22-25 April 2002.

12. Reich, G.W.; Bowman, J.C.; Sanders, B. Application of Adaptive Structures Technology to High Altitude Long Endurance Sensor Platforms. In Proceedings of the 13th International Conference on Adaptive Structures and Technologies, Potsdam, Germany, 7-9 October 2002; pp. 423-434. 
13. European Aviation Safety Agency. CS-25 Certification Specification for Large Aircraft; European Aviation Safety Agency: Cologne, Germany, 2012.

14. Engineering Science Data Unit (ESDU). Elastic Buckling of Long, Symmetrically-Laminated (ASBODF) Composite Stiffened Panels ans Struts in Compression; HIS ESDU: London, UK, 2003; Number 03001.

15. Niu, M.C. Airframe Stress Analysis and Sizing, 2nd ed.; Conmilit Press Ltd.: Hong Kong, China, 1999.

16. Rodden, W.P.; Johnson, E.H. MSC/NASTRAN Aeroelastic Analysis: User's guide Version 68; MacNeal-Schwendler Corporation: Newport Beach, CA, USA, 2004.

17. Albano, E.; Rodden, W.P. A doublet-lattice method for calculating lift distributions on oscillating surfaces in subsonic flows. AIAA J. 1969, 7, 279-285.

18. Giesing, J.P.; Kalman, T.P.; Rodden, W.P. Subsonic steady and oscillatory aerodynamics for multiple interfering wings and bodies. J. Aircr. 1972, 9, 693-702.

19. Glauert, H. The Elements of Aerofoil and Airscrew Theory; Cambridge University Press: Cambridge, UK, 1948.

20. Jaime Espinosa de los Monteros, J. A-13 Voyager. Design of the Outer Wing and Winglet in Composite Materials. M.Sc. Thesis, Cranfield University, Cranfield, UK, 2013.

21. Hexcel's Prepreg Data Sheets. Available online: http://hexcel.com/Resources/prepreg-data-sheets (accessed on 30 March 2015).

22. Wright, J.R.; Cooper, J.E. Introduction to Aircraft Aeroelasticity and Loads; American Institute of Aeronautics and Astronautics: Reston, VA, USA, 2007.

(C) 2015 by the authors; licensee MDPI, Basel, Switzerland. This article is an open access article distributed under the terms and conditions of the Creative Commons Attribution license (http://creativecommons.org/licenses/by/4.0/). 